[Agr."Biol. Chem., Vol. 36, No. 5, p. 785 792, 1972]

\title{
Oxidation of Hypoxanthine to Uric Acid by streptomyces ${ }^{+}$
}

\author{
By Yasuto Watanabe and Tatsuhiko OHE \\ Osaka Municipal Institute of Technology, \\ Kitaku, Osaka \\ Received October 4, 1971
}

\begin{abstract}
The cells of a strain of Streptomyces sp. previously grown in a peptone-glucose medium

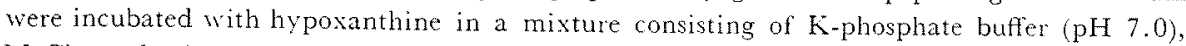
$\mathrm{IgCl}_{2}$ and glucose. Two ultraviolet absorbing substances were found to be accumulated in the mixture. One of them was identified as xanthine and the other as 6,8-dihydroxypurine from their ultraviolet absorption and chromatographic characteristics. During a further incubation, both of them disappeared from the mixture and were found to be oxidized to uric acid. Thus, the simultaneous operation of two metabolic pathways, hypoxanthine $\rightarrow$ xanthine $\rightarrow$ uric acid and hypoxanthine $\rightarrow 6,8$-dihydroxypurine $\rightarrow$ uric acid, was suggested for the oxidation of hypoxanthine by this microorganism. When the cells were incubated with hypoxanthine in the presence of chloramphenicol, xanthine and 6,8-dihydroxypurine were accumulated in the mixture and the amount of xanthine decreased during a prolonged incubation as in the absence of the antibiotic. However, 6, 8-dihydroxypurine did not decrease and uric acid was accumulated in the mixture with chloramphenicol. These oxidation pathways of hypoxanthine were found in a wide variety of Streptomyces. The enzymes which would participate in the pathways and the formation of these enzymes are discussed. A liquid chromatographic determination of hypoxanthine, 6, 8-dihydroxypurine, xanthine and uric acid using an anion exchanger column are described.
\end{abstract}

A strain of Streptomyces sp. has been found to produce a large amount of uricase (urate: oxygen oxidoreductase, EC 1.7.3.3) when the cells previously grown in a peptone-glucose medium were incubated with uric acid" or some other purine bases ${ }^{21}$ in a mixture consisting of potassium phosphate, magnesium chloride and glucose. The amount of uricase thus produced was changeable depending on the purine bases added to the mixture, and the cells incubated with hypoxanthine produced the largest amount of the enzyme. There has been very little of the studies on the catabolism of purine bases in Streptomyces, and, therefore, it seemed to be necessary to study the conversion of hypoxanthine to uric acid in this microorganism in relation to the diversity in

1 A part of this report was presented at the meeting of the Kansai Division of the Agricultural Chemical Society of Japan held in Takamatsu in October and in Osaka in December, 1971. the amount of uricase produced by the cells incubated with different purine bases.

In a course of the investigations, a fairly large amount of an ultraviolet absorbing substance, which was not identical with hypoxanthine, xanthine and uric acid, was found to be accumulated in the incubation mixture. The degradation pathway of purine bases seems to be well established in a wide variety of organisms, and it is generally considered that a main pathway of the purine base catabolism includes the oxidation of hypoxanthine to xanthine to uric acid. ${ }^{31}$ Xanthine oxidase (xanthine: oxygen oxidoreductase, EC 1.2.3.2) or xanthine dehydrogenase (xanthine: (acceptor) oxidoreductase) catalyzes these reactions. In some microorganisms, however, other pathways than the conversion of hypoxanthine to xanthine and of xanthine to uric acid appear to be also operating., ${ }^{4,5)}$ The formation of 6,8dihydroxypurine from hypoxanthine has been 
reported using intact cells of Proteus rettgeri and of Serratia marcescens, ${ }^{6,71}$ cell extracts of Clostridium cylindrosporum ${ }^{8}$ and purified xanthine dehydrogenase of Micrococcus lactilyticus. ${ }^{91}$ The present report describes the accumulation of an ultraviolet absorbing substance in the mixture in which the cells of Streptomyces sp. were incubated with hypoxanthine, and the isolation and identification of it as 6,8-dihydroxypurine. The formation of the purine derivative from hypoxanthine and its conversion to uric acid were also studied to elucidate the oxidation pathways of hypoxanthine to uric acid by this microorganism.

\section{MATERIALS AND METHODS}

The microorganism used in this study was a strain of Streptsmyces sp. isolated from the soil and stocked on a potato-agar slant as described previously.10) The organism was grown in $60 \mathrm{ml}$ of a medium (peptoneglucose medium), containing $2.0 \%$ peptone, $3.0 \%$ glucose, $0.1 \% \mathrm{~K}_{2} \mathrm{HPO}_{4}, 0.05 \% \mathrm{MgSO}_{4} \cdot 7 \mathrm{H}_{2} \mathrm{O}$ and $0.05 \% \mathrm{NaCl}$ ( $\mathrm{pH} 7.0$ ), at $27^{\circ} \mathrm{C}$ for $36 \mathrm{hr}$ with shaking. Cells were harvested on a Buchner funnel and washed 3 times with distilled water. The washed cells, $0.5 \mathrm{~g}$ in wet weight, were suspended in $20 \mathrm{ml}$ of an incubation mixture ${ }^{1 /}$ consisting of $50 \mathrm{~mm} \mathrm{~K}$ phosphate buffer ( $\mathrm{pH} 7.0$ ), $10 \mathrm{mM} \mathrm{MgCl}_{2}$ and $20 \mathrm{mM}$ glucose. To the mixture was added hypoxanthine or other purine bases in a concentration indicated in each experiment. Incubation of the mixture was carried out at $30^{\circ} \mathrm{C}$ with shaking and terminated by filtration with filter paper. In a control experiment, cells were incubated without any addition of purine bases.

The isolation of 6,8-dihydroxypurine from the incubation mixture was achieved as follows. The washed cells were incubated with $2.0 \mathrm{~mm}$ hypoxanthine in the mixture, and the ultraviolet absorption spectrum of filtrate was monitored at intervals during the incubation. When a peak at $250 \mathrm{~m} / \mathrm{in}$ an absorption spectrum of the mixture moved to $260 \mathrm{~m} /$ (see Fig. 3), the mixture was filtered to remove the cells. The filtrate, $200 \mathrm{ml}$ in total, was applied on a column of Dowex $2-\mathrm{X} 8\left(\mathrm{OH}^{-}\right.$form, $50 \sim 100$ mesh, $\left.2 \times 30 \mathrm{~cm}\right)$ and the column was washed thoroughly with distilled water until washings became neutral. The column was then eluted with $2 \mathrm{~N}$ acetic acid, and fractions of the eluate which gave an absorption at $260 \mathrm{~m} / t$ were combined.
Acetic acid and water were removed from the eluate by evaporation under reduced pressure at $40^{\circ} \mathrm{C}$. The residue was dissolved in a small amount of water by adding several drops of $1 \mathrm{~N} \mathrm{KOH}$ if necessary to make a clear solution. The solution $(5 \mathrm{ml})$ was applied on a column of Amberlite IR-120 ( $\mathrm{H}^{+}$form, 50 100 mesh, $1.5 \times 20 \mathrm{~cm}$ ) and the column was washed with distilled water until ultraviolet absorption in the effuent disappeared. Fractions of the effluent giving an absorption at $260 \mathrm{~m} /$ were combined and concentrated under reduced pressure at $40^{\circ} \mathrm{C}$. White precipitate thus obtained was crystallized from water.

For further purification, the precipitate was dissolved in a small amount of water by adding several drops of $1 \mathrm{~N} \mathrm{KOH}$ if necessary, and the solution containing about $20 \mathrm{mg}$ of 6,8-dihydroxypurine was charged on a column of Dowex 1-X2 (Cl-form, $200 \sim 400$ mesh, $3 \times 40 \mathrm{~cm}$ ) previously equilibrated with $0.05 \mathrm{M}$ phosphate buffer ( $\mathrm{pH} 8.0$ ) containing $0.3 \mathrm{M} \mathrm{NaCl}$. The column was eluted with the same buffer at a flow rate of $100 \mathrm{ml}$ per $\mathrm{hr}$, and the eluate was collected in $20 \mathrm{ml}$-fractions. The fractions of 6,8 -dihydroxypurine were combined and concentrated under reduced pressure at $40^{\circ} \mathrm{C}$. The concentrated solution was treated with the column of Dowex 2 and Amberlite IR120 successively as described above, and 6,8-dihydroxypurine was recrystallized 3 times from water.

The determination of ultraviolet absorption was carried out using a Beckman DB spectrophotometer. Filtrates of the incubation mixture were diluted appropriately with $0.05 \mathrm{M}$ phosphate buffer $(\mathrm{pH} 7.0)$ and absorbance of the dilute was read against the corresponding dilute of control run. The ultraviolet absorption spectrum of 6,8-dihydroxypurine isolated from the incubation mixture was determined in $0.05 \mathrm{M}$ ace-

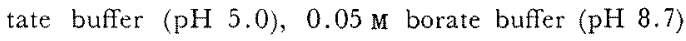
and $0.01 \mathrm{M} \mathrm{NaOH}(\mathrm{pH} \mathrm{12.0).111}$

Hypoxanthine, 6,8-dihydroxypurine, xanthine and uric acid in the incubation mixture were analyzed by ion-exchange column chromatography using a Hitachi Liquid Chromatograph 034. Dowex 1-X2 (Cl- form, $200 \sim 400$ mesh) was packed in a column $(0.9 \times 15 \mathrm{~cm})$ and equilibrated with a solution of $0.3 \mathrm{M} \mathrm{NaCl}$ in $0.05 \mathrm{M}$ phosphate buffer ( $\mathrm{pH} 7.6$ ). The elution was performed at $40^{\circ} \mathrm{C}$ with the same solution at a flow rate of $60 \mathrm{ml}$ per hr. The absorbance of the effluent was measured at 260,270 and $290 \mathrm{~m} /$ and recorded every $4 \mathrm{sec}$ on a chart moving $6 \mathrm{~cm}$ per hr. In Fig. 1 is shown a standard chromatogram of hypoxanthine, 6,8-dihydroxypurine, xanthine and uric acid prepared 


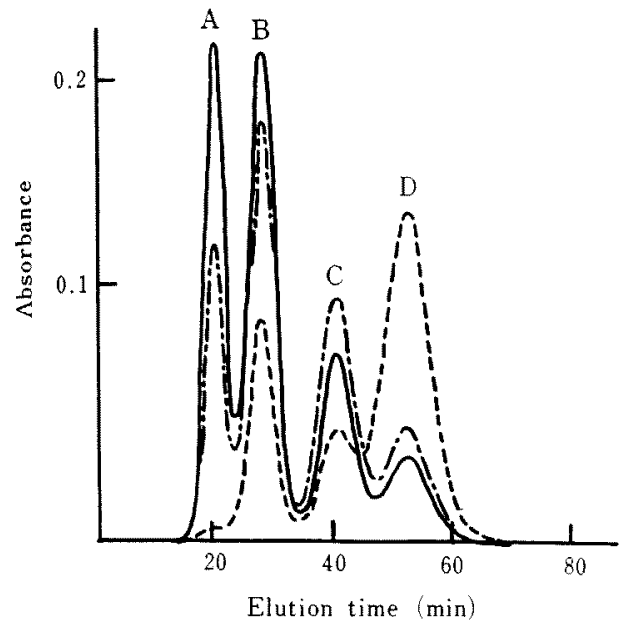

Frg. 1. Liquid Chromatography of Hypoxanthine, 6,8-Dihydroxypurine, Xanthine and Uric Acid.

The purine bases $(0.5 \mu$ moles each) were chromatographed on a Dowex 1 column as described in the text. The absorbance of the effuent was measured at $260 \mathrm{~m} \psi-, 270 \mathrm{~m} \psi-\cdots-$ and $290 \mathrm{~m} \psi$ -.... A: hypoxanthine; B: 6,8-dihydroxypurine; C: xanthine; D: uric acid.

by analyzing 0.5, moles of each purine base under the conditions mentioned above. When the elution was carried out at $\mathrm{pH} 7.4(0.3 \mathrm{M} \mathrm{NaCl}-0.05 \mathrm{M}$ phosphate buffer), the peaks of 6,8-dihydroxypurine, xanthine and uric acid were well separated from each other, but hypoxanthine and 6,8-dihydroxypurine overlaped. At pH $8.0(0.3 \mathrm{M} \mathrm{NaCl}-0.05 \mathrm{M}$ phosphate buffer), the peaks of hypoxanthine, 6,8-dihydroxypurine and xanthine were separated adequately, but xanthine and uric acid were eluted in identical fractions.

Paper chromatography of 6,8-dihydroxypurine was performed on Toyo filter paper No. 50 using $n$-butanol$5 \mathrm{~N}$ acetic acid (2:1) as developing reagent in descending method, 12 and $10 \%$ urea saturated $n$-butanol or $n$-butanol-acetic acid-water $(4: 1: 1)$ in ascending method. ${ }^{71}$ The spot of the purine base was detected under an ultraviolet lamp.

Preparation of sonic extracts of the cells and determination of uricase activity in the extracts were carried out as described previously. 10

Hypoxanthine, xanthine and uric acid were purchased from Wako Pure Chemical Industries, Ltd. and chloramphenicol was a product of Sankyo Co., Ltd.
Other reagents used were the highest grade commercially available.

\section{RESULTS}

Ciells of Streptomyces sp. previously grown for $36 \mathrm{hr}$ in a peptone-glucose medium were incubated in a mixture containing $2.0 \mathrm{~mm}$ hypoxanthine (see Materials and Methods). A typical time course of decrease in absorbance at $250 \mathrm{~m} \mu$ of the mixture during the incubation is shown in Fig. 2. Ultraviolet absorption spectrum of the mixture is also shown in Fig. 3. It was found that an absorption maximum of the spectrum was shifted from $250 \mathrm{~m}$ t: to $265 \mathrm{~m} / \mathrm{d}$ during the incubation.

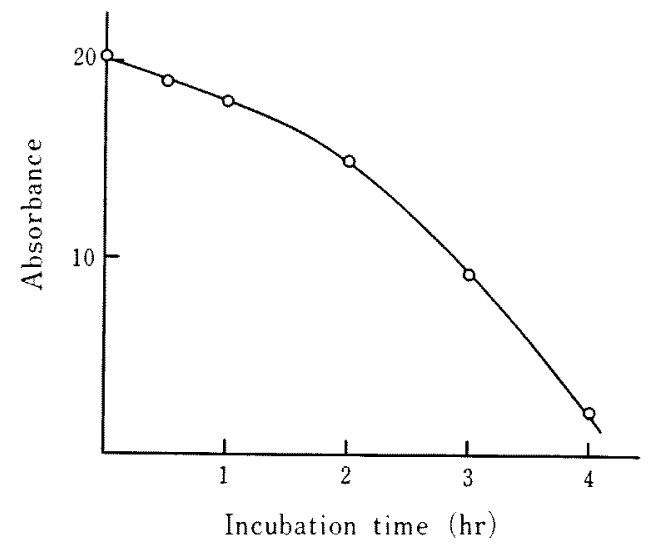

FIG. 2. Decrease in the Ultraviolet Absorption of the Incubation Mixture.

The absorbance was measured at $250 \mathrm{~m} \mu$ at $\mathrm{pH}$ 7.0.

Ion-exchange column chromatography of the incubation mixture indicated the formation of two ultraviolet absorbing substances as shown in Fig. 4. One was identified as xanthine from the elution position in the chromatogram and the ratio of the absorbances at three wavelengths $(260,270$ and $290 \mathrm{~m} \mu)$. The other was eluted from the column between hypoxanthine and xanthine and was isolated from the mixture as described in the Methods. By apply- 


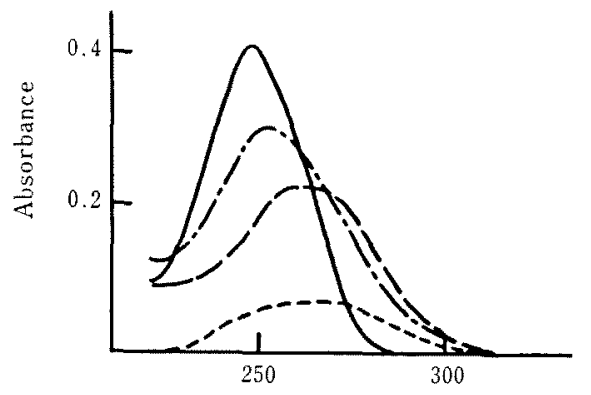

Wave length $(\mathrm{m} \mu)$

FIG. 3. Changes in the Ultraviolet Absorption Spectrum of the Incubation Mixture.

The spectrum was determined at $\mathrm{pH} 7.0$ at 0 $\ldots, 2 \ldots-., 3 \ldots$ and $4 \mathrm{hr} \ldots$ of the incubation.

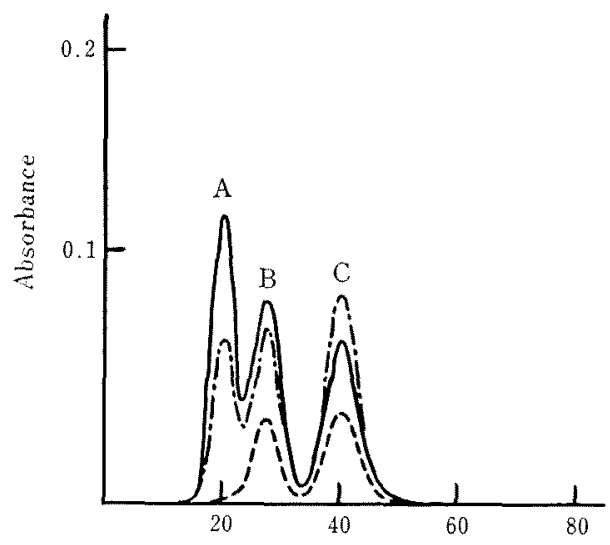

Elution time $(\mathrm{min})$

FIG, 4. Liquid Chromatogram of the Mixture Incubated with Hypoxanthine.

A $0.5 \mathrm{ml}$ aliquot of the incubation mixture in which the cells were incubated with $2 \times 10^{-3} \mathrm{M}$ of hypoxanthine was taken at $4 \mathrm{hr}$ of the incubation and subjected to 1 liquid chromatography. A: hypoxanthine; B: 6,8-dihydroxypurine; $C$ : xanthine.

ing the chromatographic technics, this ultraviolet absorbing substance could be obtained as white plate crystals, and was identified as 6,8-dihydroxypurine from its ultraviolet absorption and paper chromatographic character- istics. Ultraviolet absorption spectra of the crystal substance as aqueous solution at three different $\mathrm{pH}$ 's are shown in Fig. 5. The absorption characteristics and paper chromatographic behaviors of the substance are summerized and are compared with those reported in leteratures ${ }^{711-13)}$ in Tables I and II.

In order to elucidate the metabolic pathways of hypoxanthine oxidation in this microorganism, the washed cells were incubated with $0.5 \mathrm{~mm}$ hypoxanthine in the absence or presence of chloramphenicol. Filtrates were taken at intervals and subjected to the liquid chromatographic analyses of purine bases. As shown in Fig. 6, conversion of hypoxanthine

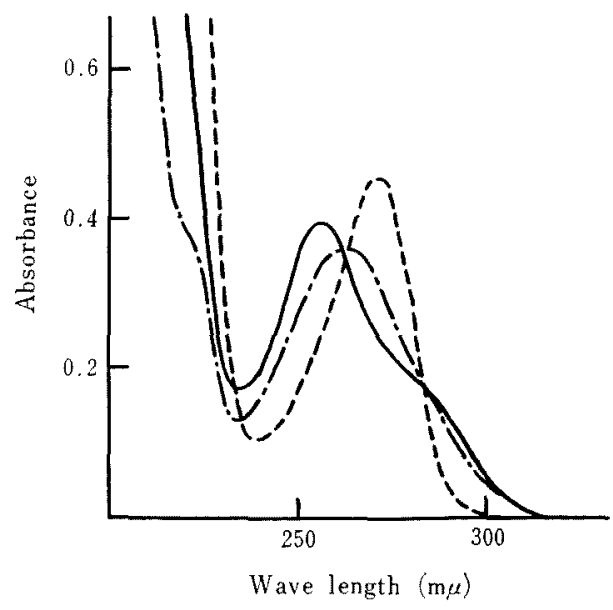

FIG. 5. Ultraviolet Absorption Spectra of the Isolated 6,8-Dihydroxypurine Determined at Different pH's.

pH $5.0,-;$ pH $8.7, \ldots \ldots ;$ pH $12.0, \ldots$.

Table I. Ultraviolet ABsorption CharacterISTICS OF THE ISOLATED 6,8-DIHYDROXYPURINE

\begin{tabular}{rcccc}
\hline $\mathrm{pH}$ & \multicolumn{2}{c}{ Sample } & \multicolumn{2}{c}{ Leterature $^{111}$} \\
\cline { 2 - 4 } & $\lambda_{\mathrm{max}}(\mathrm{m} \mu)$ & $\varepsilon\left(\times 10^{4}\right)$ & $\lambda_{\max }(\mathrm{m} \mu)$ & $\varepsilon\left(\times 10^{4}\right)$ \\
\hline 5.0 & 256 & 1.20 & 257 & 1.20 \\
& 280 & 0.596 & 280 & 0.575 \\
8.7 & 263 & 1.09 & 265 & 1.10 \\
12.0 & 271 & 1.38 & 271 & 1.38 \\
\hline
\end{tabular}


Table II. PaPer Chromatographic Behaviors of THE ISOLATED 6,8-DIHYDROXYPURINE

\begin{tabular}{|c|c|c|c|}
\hline \multirow{2}{*}{ Developing reagent } & \multirow{2}{*}{ Method } & \multicolumn{2}{|r|}{$R f$} \\
\hline & & Sample & Leterature \\
\hline $\begin{array}{l}\mathrm{BuOH}-5 \mathrm{~N} \text { AcOH } \\
(2: 1)\end{array}$ & Descending & 0.40 & 0.4012 \\
\hline $\begin{array}{l}10 \% \text { Urea satd. } \\
\text { BuOH }\end{array}$ & Ascending & 0.19 & $0.20^{7 i}$ \\
\hline $\begin{array}{l}\mathrm{BuOH}-\mathrm{AcOH}-\mathrm{H}_{2} \mathrm{O} \\
(4: 1: 1)\end{array}$ & Ascending & 0.27 & $0.26^{7}$ \\
\hline
\end{tabular}

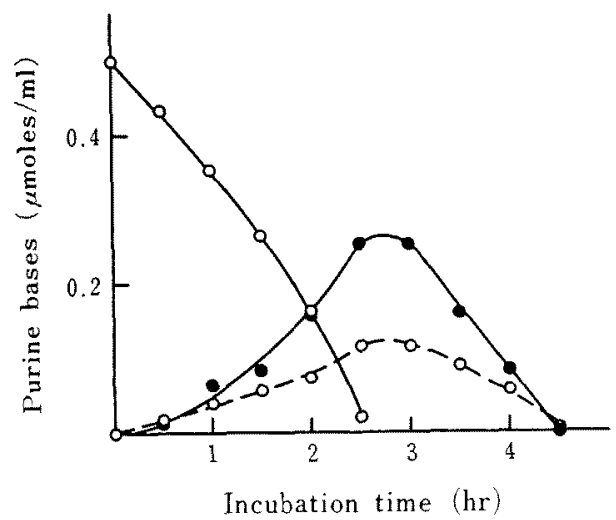

FIG. 6. Purine Bases in the Mixture Incubated with Hypoxanthine.

The cells were incubated with $0.5 \times 10^{-3} \mathrm{M}$ of hypoxanthine, and aliquots of the incubation mixture were taken at intervals and subjected to the liquid chromatography to determine hypoxanthine $0-0,6,8$-dihydroxypurine $0 \cdots 0$ and xanthine - No uric acid was detected in the mixture during the incubation.

to xanthine and 6,8-dihydroxypurine occurred without accumulation of uric acid in the mixture during the incubation in the absence of chloramphenicol. The rate of oxidation of hypoxanthine increased slightly during the incubation, and the amount of xanthine and 6,8-dihydroxypurine accumulated in the mixture increased as hypoxanthine decreased, reaching the maximum at the time when hypoxanthine vanished from the mixture. The sum of these purine bases accumulated was corresponded to about 70 to $80 \%$ of hypoxanthine added to the incubation mixture. After the disappearance of hypoxanthine, xanthine and 6,8-dihydroxypurine in the mixture began to decrease and vanished at $4.5 \mathrm{hr}$-incubation.

Analyses of purine bases in the mixture incubated in the presence of $1.0 \mathrm{mg} \%$ chloramphenical are shown in Fig. 7. Prominent

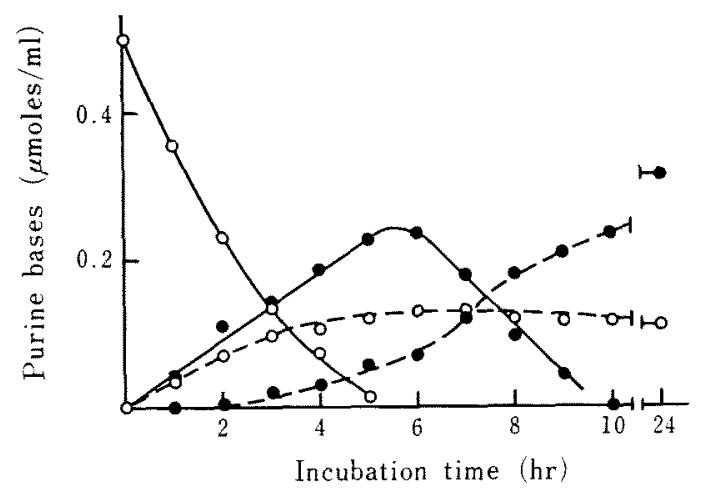

FIG. 7. Purine Bases in the Mixture Incubated with Hypoxanthine in the Presence of Chloramphenicol.

The cells were incubated with $0.5 \times 10^{-3} \mathrm{M}$ of hypoxanthine in the presence of $1.0 \mathrm{mg} 0_{0}$ of chloramphenicol, and aliquots of the incubation mixture were taken at intervals and subjected to the liquid chromatography to determine hypoxanthine $0-0,6,8$-dihydroxypurine $\bigcirc-\cdots$, xanthine - and uric acid

differences in the purine base catabolism by the cells brought about by the addition of the antibiotic were as follows: 6,8-dihydroxypurine accumulated in the mixture did not decrease during $24 \mathrm{hr}$-incubation, and uric acid was accumulated. Xanthine once accumulated together with 6,8-dihydroxypurine decreased and disappeared from the mixture during a further incubation even in the presence of chloramphenicol. About $90 \%$ of hypoxanthine added to the mixture were recovered as xanthine, 6,8-dihydroxypurine and uric acid in the mixture at a time when hypoxanthine disappeared, and the same level of the recovery as 6,8dihydroxypurine and uric acid was also ob- 
served at $24 \mathrm{hr}$-incubation.

The washed cells were incubated with xanthine or with 6,8-dihydroxypurine in a concentration of $1.0 \mathrm{~mm}$, and the filtrates of the incubation mixture were taken at intervals and analized by the liquid chromatography. Only a small amount of uric acid was found to be accumulated in the mixture incubated with xanthine, and almost no purine base other than the substrate was observed in the mixture incubated with 6,8-dihydroxypurine. ${ }^{141}$ The cells incubated with xanthine or 6,8-dihydroxypurine were taken at a time when ultraviolet absorption disappeared from the mixture, and uricase activity in the sonic extracts of the cells was assayed. About 4 units of the enzyme activity per $g$ of wet cells was detected in both cases.

In order to examine whether these pathways of hypoxanthine oxidation are specific to this organism or are general in Streptomyces, several species belonging to this genus were grown in the peptone-glucose medium and the cells were incubated with hypoxanthine in a concentration of $2.0 \mathrm{~mm}$. As seen in Table III, most of the species examined were found to produce 6,8-dihydroxypurine and xanthine, although the amount of the purine bases recovered in the incubation mixture was much smaller than that observed in the mixture incubated with the strain used throughout this study.

\section{DISGUSSION}

The cells of a strain of Streptomyces sp. used in this investigation appears to be specific in that a considerable part of oxidation products in the purine base catabolism is released and accumulated in the medium. When the cells of this microorganism were incubated with hypoxanthine in a mixture containing potassium phosphate, magnesium chloride and glucose, ultraviolet absorbing substances other than the substrate were accumulated in the incubation mixture. These substances were identified as xanthine and 6,8-dihydroxypurine. Since the following two findings were obtained: (1) no interconversion between xanthine and 6,8-dihydroxypurine, and (2) conversion of these two purine bases to uric acid, two metabolic pathways was suggested for the oxidation of hypoxanthine to uric acid by this organism; (1) hypoxanthine $\rightarrow$ xanthine $\rightarrow$ uric acid

Table III. Oxidation Products of Hypoxanthine by Several Species of Streptomyces

The cells were incubated with $2 \times 10^{-3} \mathrm{M}$ of hypoxanthine in the absence or presence of $1.0 \mathrm{mg} \%$ of chloramphenicol. The mixtures were taken at intervals and subjected to the liquid chromatography. The largest amount of each purine base found during the incubation is shown by the relative number of +

\begin{tabular}{|c|c|c|c|c|c|c|c|}
\hline \multirow[b]{2}{*}{ Organism } & \multicolumn{3}{|c|}{ without Chloramphenicol } & \multicolumn{4}{|c|}{ with Chloramphenicol } \\
\hline & $\begin{array}{l}\text { 6,8-Dihydroxy- } \\
\text { purine }\end{array}$ & Xanthine & $\begin{array}{l}\text { Uric } \\
\text { acid }\end{array}$ & $\begin{array}{l}\text { 6,8-Dihydroxy- } \\
\text { purine }\end{array}$ & Xanthine & $\begin{array}{l}\text { Uric } \\
\text { acid }\end{array}$ & Unknown \\
\hline St. griseus & + & H & + & + & $H$ & \pm & \\
\hline scabies & + & 世 & + & - & - & - & $H$ \\
\hline olivaceus & - & H & + & - & + & + & \\
\hline lipmanii & + & $H$ & + & H & 册 & $H$ & \\
\hline griseolus & H & H & H & H & H & + & \\
\hline albus & - & - & - & - & - & - & \\
\hline diastaticus & H & HH & $H$ & $H$ & $H$ & - & \\
\hline viridochromogenes & + & $H$ & + & + & $H$ & - & \\
\hline sp. & 冊 & H⿻川 & \pm & H & 册 & $H$ & \\
\hline
\end{tabular}


and (2) hypoxanthine $\rightarrow$ 6,8-dihydroxypurine $\rightarrow$ uric acid. These pathways appeared to be functioning simultaneously. In the presence of chloramphenicol, 6,8-dihydroxypurine derived from hypoxanthine was not changed any more, and xanthine from the substrate was oxidized to uric acid. Uric acid was also hardly oxidized in the presence of the antibiotic. Therefore, the accumulation of uric acid in the mixture may represent the conversion of the substrate to uric acid by the way of xanthine, and it seems that hypoxanthine would be oxidized to xanthine and 6,8-dihydroxypurine in a ratio of $3: 1$. These pathways of hypoxanthine oxidation to uric acid seemed to be operating in most species of Streptomyces.

In case of mammalian xanthine oxidase, a single enzyme seems to catalyze all of these reactions, such as the oxidations of hypoxanthine to uric acid via xanthine and 6,8dihydroxypurine. ${ }^{15,16)}$ In this microorganism, however, it seems that the single enzyme system is not acceptable. Probably xanthine dehydrogenase might be one of the enzymes responsible for these reactions. Whether a single xanthine dehydrogenase catalyzes the oxidation of hypoxanthine to xanthine and to 6,8-dihydroxypurine or separate enzymes are responsible for each reaction is not certain from the results obtained in the present investigations. An enzyme which catalyzes the oxidation of 6,8-dihydroxypurine to uric acid is distinct obviously from enzymes catalyzing the conversions of hypoxanthine to both xanthine and 6,8-dihydroxypurine and of xanthine to uric acid, since the latter activities were all noted in the cells even in the presence of chloramphenicol, whereas the oxidation of 6,8-dihydroxypurine could only be observed in the absence of the antibiotic. This may suggest that an enzyme catalyzing the conversion of $6,8-$ dihydroxypurine to uric acid does not exist or exists in a very small quantity, if any, in the cells grown in the peptone-glucose medium for $36 \mathrm{hr}$, in contrast to enzymes catalyzing the oxidation of hypoxanthine and of xanthine. This enzyme might be specific for the oxidation of 6,8-dihydroxypurine to uric acid or for the oxidation at position 2 of purine bases which have already been oxidized at position 8. The presence of 2-oxypurine dehydrogenase which differs from xanthine dehydrogenase and catalyzes the oxidation of purine bases exclusively at position 6 has been reported. ${ }^{17}$

Although almost no activity of the 6,8-dihydroxypurine oxidizing enzyme was detected in the cells grown in the peptone-glucose medium for $36 \mathrm{hr}$, the enzyme was produced rapidly in the cells incubated in a mixture containing potassium phosphate, magnesium chloride and glucose. The formation of the enzyme appeared to be induced by the substrate added to the mixture or generated in the cells from hypoxanthine. It has also been found that the activity of uricase of this microorganism is negligible in the cells grown in the peptone-glucose medium for $36 \mathrm{hr}^{101}$ and that the formation of the enzyme is induced by uric acid in the cells incubated in the mixture." It would be presumed that the formation of the enzymes catalyzing the oxidation of 6,8-dihydroxypurine and of uric acid is regulated by similar mechanisms which may be different from those controlling the formation of the enzymes catalyzing the oxidation of hypoxanthine and of xanthine.

\section{REFERENCES}

I) Y. Watanabe and J. Fukumoto, Agr. Biol. Chem., 33. 1625 (1970).

2) Y. Watanabe, ibid., 35, 2008 (1971).

3) S. C. Hartman, "Metabolic Pathways," 3rd ed., Vol. IV, ed. by D. M. Greenberg, Academic Press, Inc., New York, N.Y., 1970, p. 1.

4) J. C. Rabinowitz and W. E. Pricer, Jr., J. Biol. Chem., 218, 189 (1956).

5) A. J. Darlington and C. Scazzocchio, Biochim. Biophys. Acta, 166, 569 (1968).

6) S. Eguchi, S. Okumura and N. Katsuya, Japanese Patent 6250 (1967) [C.A., 68, $48307 \mathrm{~m}$ (1968)].

7) A. Mimura, T. Akimoto and R. Kodaira, Hak- 
ko-Kogaku Zasshi, 47, 268 (1969).

8) W. H. Bradshaw and H. A. Barker, J. Biol Chem., 235, 3620 (1960).

9) S. T. Smith, K. V. Rajagopalan and P. Handler, ibid., 242, 4108 (1967).

10) Y. Watanabe, M. Yano and J. Fukumoto, Agr. Biol. Chem., 33, 1282 (1969).

11) S. F. Mason, J. Chem. Soc., 1954, 2071.

12) A. Albert and D. J. Brown, ibid., 1954, 2060.

13) L. F. Cavalieri and A. Bendich, $J$. Am. Chem.
Soc., 72, 2587 (1950).

14) $Y$. Watanabe, in preparation.

15) F. Bergmann and S. Dikstein, J. Biol. Chem., 223, 765 (1956).

16) R. C. Bray, "The Enzymes," 2nd ed., Vol. VII, ed. by P. D. Boyer, H. Lardy and K. Myrbäck, Academic Press, Inc., New York, N.Y., 1963, p. 533 .

17) C. A. Woolfolk, B. S. Woolfolk and H. R. Whiteley, J. Biol. Chem., 245, 3167 (1970). 